\title{
Adsorptive Removal of As(III) from Aqueous Solution
}

\author{
Pushpa Bhattarai, Khagendra Prasad Bohara, Megh Raj Pokhrel* \\ Central Department of Chemistry \\ Tribhuvan University, Kirtipur, Kathmandu, Nepal \\ *E-mail:-meghraj11@hotmail.com
}

\begin{abstract}
The iron-modified Dalbergia sissoo sawdust was synthesized by loading iron (III) onto phosphorylated Dalbergia sissoo sawdust via soaking in a ferric salt solution. Batch studies were performed at an initial concentration of $1 \mathrm{mg} / \mathrm{l}$ to evaluate the effect of parameters such as $\mathrm{pH}$, equilibrium time, adsorbent dose and concentration of adsorbate. Kinetics and isotherm modeling studies demonstrated that the experimental data best fit a pseudo-first order and Langmuir isotherm model, respectively. The maximum adsorption capacity was found to be $1.33 \mathrm{mg} / \mathrm{g}$ for As(III) onto FePDSD suggesting the suitability of chemically modified Dalbergia sissoo sawdust for the adsorptive removal of As(III) from aqueous solution.
\end{abstract}

Key words: Arsenic (III), adsorption, iron (III), saw dust

\section{INTRODUCTION}

Arsenic, a toxic and carcinogenic element, contamination of underground water is a global environmental problem affecting a large number of populations (Nickson et al. 1998, Lee et al. 2003, Mandal \& Suzuki 2002). Common species of dissolved arsenic in water are the anionic species of As(III) and As(V) (Chutia et al. 2009). However, the predominant form in reduced environment is $\mathrm{As}(\mathrm{III})$, though due to slow redox kinetics both forms are often found in either environment. Arsenite is more toxic than arsenate and is reported to be more mobile in the environment (Bohara 2005, Lien \& Wilkin 2005). The World Health Organization provisional guideline value for arsenic in drinking water is $10 \mu \mathrm{g} / \mathrm{l}$ (WHO 2004). However, the provisional guideline value of arsenic in drinking water in Nepal is $50 \mu \mathrm{g} / 1$ (Neku \& Tandukar, 2003).

Several technologies are available for the removal of arsenic from aqueous media. These employ the processes such as co-precipitation, oxidation, coagulation, adsorption, ion exchange, membrane processes, or biological removal at once or in sequence (Bohara 2005, Lee et al. 2003). Among the methods adsorption is one of the popular and effective processes due to its versatility in the use of adsorbents. Recently, biosorption is emerging as a potent alternative to the existing conventional technology for the removal of toxic ions from aqueous solutions since it offers flexibility in design and operation with the advantages such as: low cost, high efficiency, minimization of chemical or biological sludge, regeneration of bio-sorbents and possibility of metal recovery (Sud et al. 2008, Bailey et al. 1999). The effectiveness of natural and chemically modified form of different biological materials towards the adsorptive removal of arsenic has been studied by a number of researchers (Rahaman et al. 2008, Al-Mamun et al. 2009, Kamsonlian et al. 2011, Ghimire et al. 2003, Islam et al. 2007, Murugesan et al. 2006, Mamisahebei et al. 2007, Ranjan et al. 2009, Yang et al. 2010, and Wu et al. 2012). Under such circumstances, our aim was to prepare lowcost adsorbent from Dalbergia sissoo sawdust and to investigate its capacity towards the adsorptive removal of As(III) from aqueous solution.

\section{MATERIALS AND METHODS}

\section{Chemicals}

All the chemicals were of reagent grade and were used without any further purification. $\mathrm{As}_{2} \mathrm{O}_{3}$, was used as the source of $\mathrm{As}(\mathrm{III}) . \mathrm{H}_{3} \mathrm{PO}_{4}$, dimethyl formamide, $\mathrm{NH}_{2} \mathrm{CONH}_{2}, \mathrm{FeCl}_{3}$, propanol were used to prepare the adsorbent from Dalbergia sissoo sawdust. Laboratory distilled water was used for the preparation of reagent solutions and standard arsenite samples.

\section{Preparation of adsorbent}

Crude Dalbergia sissoo sawdust was exposed to sunlight for 6 hours, the dried sawdust was sieved to pass mesh size of 212 micron and was stored in clean and dry polyethylene bottle which was considered as raw Dalbergia sissoo sawdust (RDSD).

A weight of $20 \mathrm{~g}$ of RDSD was soaked in $250 \mathrm{ml}$ concentrated dimethyl formamide in a $500 \mathrm{ml}$ three 
necked flask equipped with magnetic stirrer and was stirred for an hour, and left overnight. Then $30 \mathrm{~g}$ urea was added in the three necked flask followed by $30 \mathrm{ml}$ of $85 \%$ orthophosphoric with constant stirring. The whole content was stirred for 1 hour at room temperature, and then refluxed for 2 hours at $150^{\circ} \mathrm{C}$ with continuous stirring using paraffin oil bath. After cooling to room temperature, the mass was washed with $700 \mathrm{ml}$ of $70 \%$ aqueous propanol, followed by washing with water up to neutrality. Then the neutral mass so obtained was activated by soaking in $250 \mathrm{ml}$ of $0.1 \mathrm{~N}$ hydrochloric acid for 1 hour in $500 \mathrm{ml}$ beaker, the supernatant was rejected and the residue left was washed with distilled water several times till neutrality was achieved. The solid mass so obtained was sun dried for 12 hours followed by drying in convection oven for 12 hours at $70^{\circ} \mathrm{C}$. The dry solid mass was termed as phosphorylated Dalbergia sissoo sawdust (PDSD) (Ghimire et al. 2003).

A weight of $4 \mathrm{~g}$ of PDSD was soaked in $400 \mathrm{ml}$ of $0.2 \mathrm{M}$ aqueous solution of anhydrous ferric chloride in $500 \mathrm{ml}$ beaker, and stirred for 6 hours, and was kept in contact for 24 hours. Then the supernatant was carefully transferred and the residue left was washed with distilled water till neutrality was achieved. The solid product was dried in a convection oven for 12 hours at $80^{\circ} \mathrm{C}$, and was termed as iron (III) - loaded phosphorylated Dalbergia sissoo sawdust (FePDSD). It was stored in clean and dry polyethylene bottle and was considered as potential adsorbent for the adsorptive removal of As(III) from aqueous solution.

\section{Adsorption tests}

The adsorption of arsenite (As(III)) ions onto iron (III) - loaded phosphorylated Dalbergia sissoo sawdust (FePDSD) was investigated by performing experiments in $100 \mathrm{ml}$ stoppered reagent bottles using $50 \mathrm{ml}$ of the $\mathrm{pH}$ adjusted standard arsenite sample solutions and $50 \mathrm{mg}$ or as per requirement of iron (III)- loaded phosphorylated Dalbergia sissoo sawdust (FePDSD) in batch adsorption equilibrium mode. The $\mathrm{pH}$ of the As(III) sample solution was adjusted by using $\mathrm{HCl}$ and $\mathrm{NaOH}$ solutions. The stoppered bottles were shaken for definite length of time in a mechanical shaker to attain equilibrium. The equilibrated solutions were filtered using filter paper and the filtrates were analyzed for the residual concentration of As(III) by the molybdenum blue method by using WPAS-104 Spectrophotometer using $1 \mathrm{~cm}$ cuvette. All experiments were performed in triplicate.

The percentage removal of arsenic was calculated from the following equation.
\% Removal $=\frac{\mathrm{C}_{\mathrm{i}}-\mathrm{C}_{\mathrm{f}}}{\mathrm{C}_{\mathrm{i}}} \times 100$
where,

$\mathrm{C}_{\mathrm{i}}=$ Initial concentration of arsenic

$\mathrm{C}_{\mathrm{f}}=$ Final concentration of arsenic

The amount of adsorbate adsorbed in $\mathrm{mg} / \mathrm{g}$ at equilibrium is computed by the following equation.

$\mathrm{q}=\frac{\left(\mathrm{C}_{\mathrm{i}}-\mathrm{C}_{\mathrm{e}}\right) \mathrm{V}}{\mathrm{where}, \quad \mathrm{M} / \mathrm{g}}$

$\mathrm{C}_{\mathrm{i}}=$ Initial concentration of arsenic in $\mathrm{mg} / \mathrm{l}$

$\mathrm{C}_{\mathrm{e}}=$ Final or equilibrium concentration of arsenic in $\mathrm{mg} / \mathrm{l}$

$\mathrm{V}=$ Volume of adsorbate solution in liter

$\mathrm{M}=$ Weight of adsorbent in $\mathrm{g}$

\section{RESULTS AND DISCUSSION}

\section{Effect of $\mathbf{p H}$}

The effect of $\mathrm{pH}$ on the adsorption efficiency of As(III) on the adsorbent prepared (FePDSD) is shown in Fig.1 which shows optimum adsorption of $\mathrm{As}(\mathrm{III})$ onto FePDSD was achieved at $\mathrm{pH} 9$.

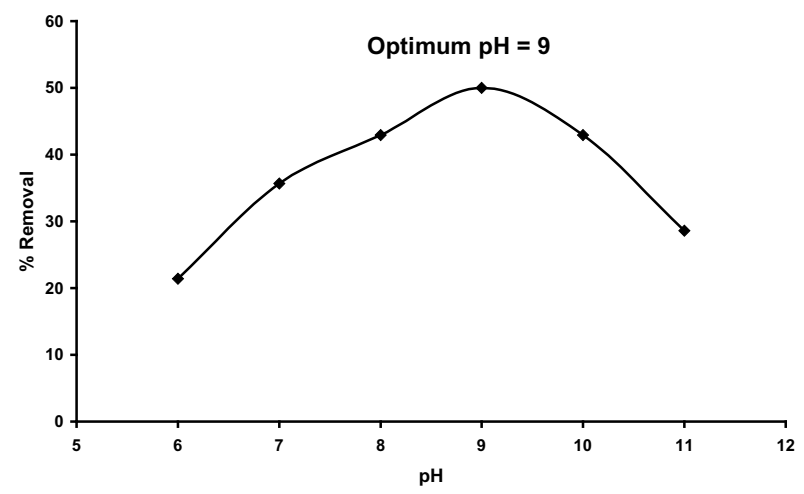

Fig. 1. Effect of $\mathrm{pH}$ in the removal of $\mathrm{As}$ (III) onto FePDSD

This can be explained by the fact that in the $\mathrm{pH}$ range $0-9, \mathrm{As}(\mathrm{III})$ exists as neutral $\mathrm{H}_{3} \mathrm{AsO}_{3}$ therefore protons can compete with neutral $\mathrm{H}_{3} \mathrm{AsO}_{3}$ in forming a bond with the surface active sites (Ghimire et al. 2003). These bonded active sites become saturated with $\mathrm{H}+$ and was inaccessible to $\mathrm{H}_{3} \mathrm{AsO}_{3}$. In addition when $\mathrm{pH}$ increases, there is decrease in positive surface charge because of the deprotonation of the adsorbent functional groups which results in lower electrostatics repulsion between the $\mathrm{H}_{3} \mathrm{AsO}_{3}$ and the surface of FePDSD favoring adsorption i.e. with increase in $\mathrm{pH}$ of the solution, charges on the surface of FePDSD becomes negative thereby leading to a increase in attractive forces between $\mathrm{H}_{3} \mathrm{AsO}_{3}$ and, FePDSD, which results in the enhancement of adsorption of $\mathrm{As}(\mathrm{III})$ and maximum adsorption of $\mathrm{As}(\mathrm{III})$ from solution. Similar results were reported by and Kamsonlian et al. for adsorption of As(III) onto powdered maize leaves biomass (Kamsonlian et al. 2011). 


\section{Effect of adsorbent dose}

The effect of adsorbent dose on the adsorption efficiency of As(III) by FePDSD is shown in Fig. 2 which shows that the removal of As(III) was found to increase with an increase in adsorbent dose.

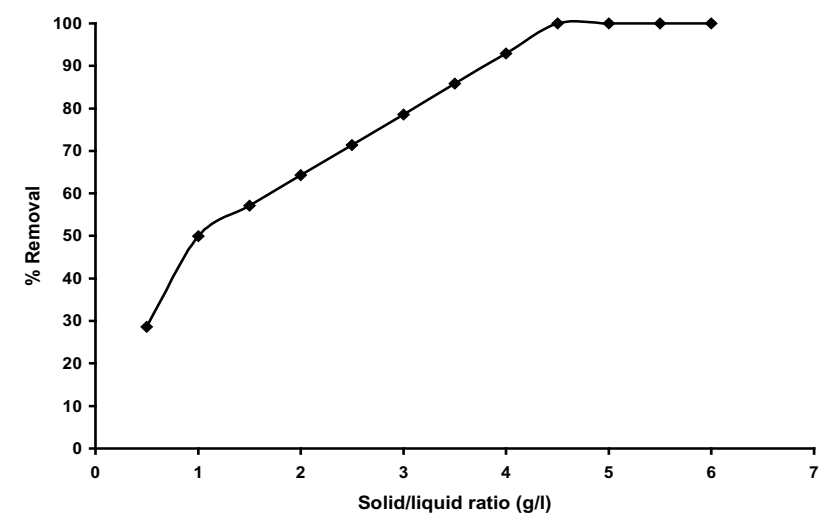

Fig. 2. Effect of adsorbent dose on the removal efficiency of As(III) onto FePDSD

The removal remains almost unchanged after adsorbent dose of $225 \mathrm{mg}$. Increase in adsorption with increase in adsorbent dose is attributed to the availability of large surface area and more adsorption sites. At low adsorbent dose, the adsorbent surface becomes saturated with As(III) and the residual As(III) ion concentration in the solutions is large enough ( $\mathrm{Su} \&$ Puls 2001).

\section{Effect of contact time}

The effect of contact time on the adsorption of $1 \mathrm{mg} / \mathrm{l}$ As(III) with $50 \mathrm{mg}$ of adsorbent is shown in Fig. 3 which shows that the equilibrium contact time for adsorption of As(III) onto FePDSD reached within 300 minutes, for FePDSD and beyond that saturation reached.

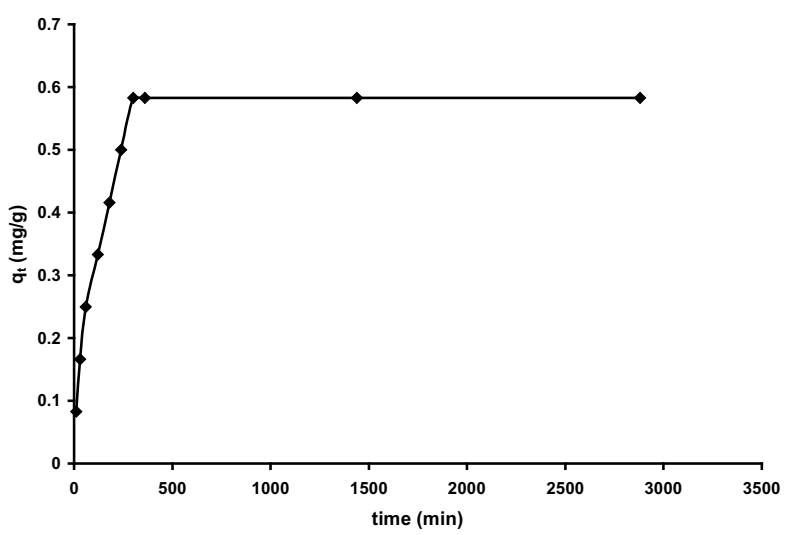

Fig. 3. Effect of equilibration time in the adsorption of As(III) onto FePDSD

The adsorption rate was rapid at first because of the presence of large number of adsorption sites so that large amount of As(III) ions get attached selectively to the adsorbent sites initially. The rate slowed down gradually till it attained equilibrium at specific time beyond which there was no significant increase in adsorption rate due to decrease in active sorption sites in the adsorbent and after the saturation point adsorption becomes constant.

\section{Effect of initial cconcentration}

The effect of As(III) concentration is shown in Fig. 4 which showed that adsorption of As(III) onto the adsorbent increases with an increase in initial concentration of $\mathrm{As}(\mathrm{III})$ and attains equilibrium, which is attributed to the availability of limited sorption sites.

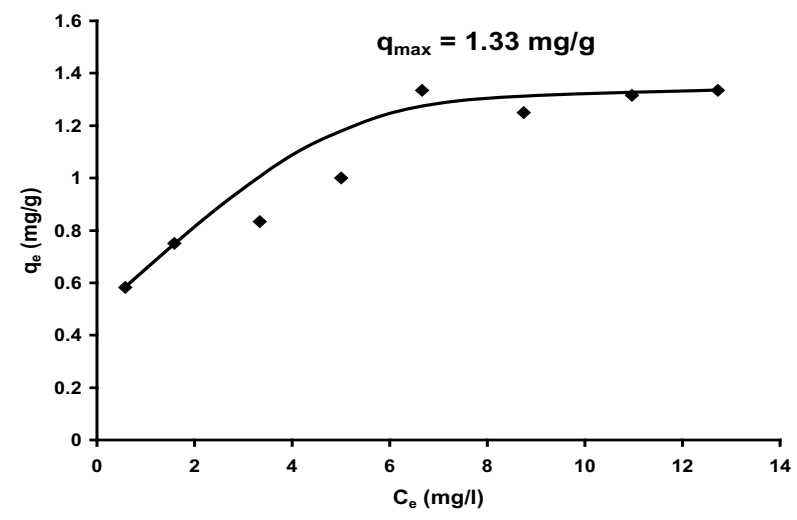

Fig. 4. Adsorption isotherm for the adsorption of As(III) onto FePDSD

The increase in concentration of As(III) increases the mass transfer driving force and therefore increases the rate at which As(III) ions pass from the bulk to the surface which would results in higher adsorption. It was found that on changing the initial concentration of As(III) from $1.16 \mathrm{mg} / \mathrm{l}$ to $14.06 \mathrm{mg} / \mathrm{l}$ the amount adsorbed increased from $0.58 \mathrm{mg} / \mathrm{g}$ to $1.33 \mathrm{mg} / \mathrm{g}$ at the optimum $\mathrm{pH}$ signifying that the adsorbent was found to be effective for the adsorptive removal of As(III).

\section{Adsorption isotherms}

The experimental data for the adsorptive removal of As(III) from aqueous solution was analyzed by using Langmuir and Freundlich models.

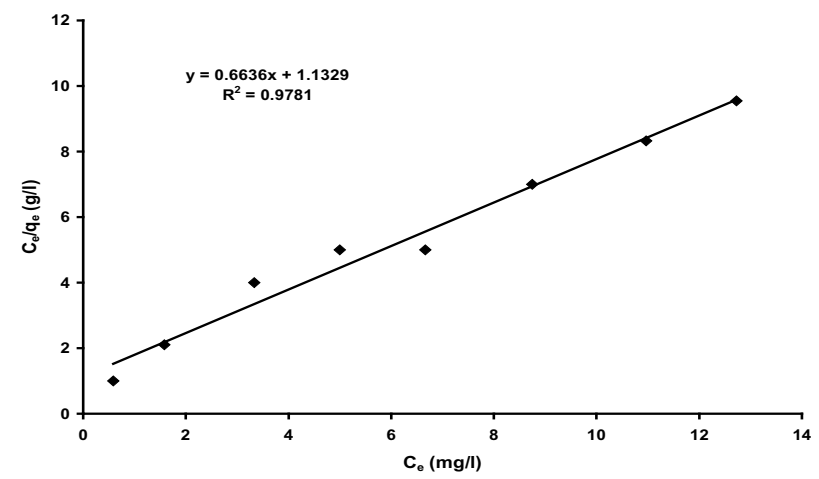

Fig. 5. Langmuir adsorption isotherm for the adsorption of As(III) onto FePDSD 
The values of Langmuir equilibrium parameter between 0 and 1 indicated that equilibrium data fits well with Langmuir adsorption isotherm. The values of $1 / \mathrm{n}$ between 0 and 1 indicated that adsorption process was favorable.

However, the correlation coefficient values for Langmuir isotherms were found to be greater than that of Freundlich isotherms(not shown) indicating that the adsorption process is better defined by the Langmuir adsorption isotherm model than by the Freundlich, indicating the homogeneous distribution of active sites on the surface of adsorbents. The monolayer sorption capacity of FePDSD for As(III) was found to be $1.50 \mathrm{mg} / \mathrm{g}$.

Table 1. Langmuir and Freundlich Parameters for the adsorption of As(III) onto FePDSD

\begin{tabular}{|l|l|l|l|l|l|l|l|l|}
\hline \multirow{2}{*}{ Species } & \multirow{2}{*}{ Adsorbent } & \multirow{2}{*}{$\begin{array}{l}\text { qm(mg/g) } \\
\text { Experimental }\end{array}$} & \multicolumn{2}{|l|}{ Langmuir isotherm } & \multicolumn{3}{|l|}{ Freundlich isotherm } \\
\cline { 3 - 9 } & & & $\mathrm{qm}(\mathrm{mg} / \mathrm{g})$ & $\mathrm{b}(\mathrm{L} / \mathrm{mg})$ & $\mathrm{R}^{2}$ & $\mathrm{~K}(\mathrm{mg} / \mathrm{g})$ & $1 / \mathrm{n}$ & $\mathrm{R}^{2}$ \\
\hline As(III) & FePDSD & 1.33 & 1.50 & 0.586 & 0.978 & 0.654 & 0.310 & 0.918 \\
\hline
\end{tabular}

\section{Kinetic modeling}

The kinetics for the adsorption of As(III) onto FePDSD was analyzed using pseudo-first order, Pseudo-second order and second order models.

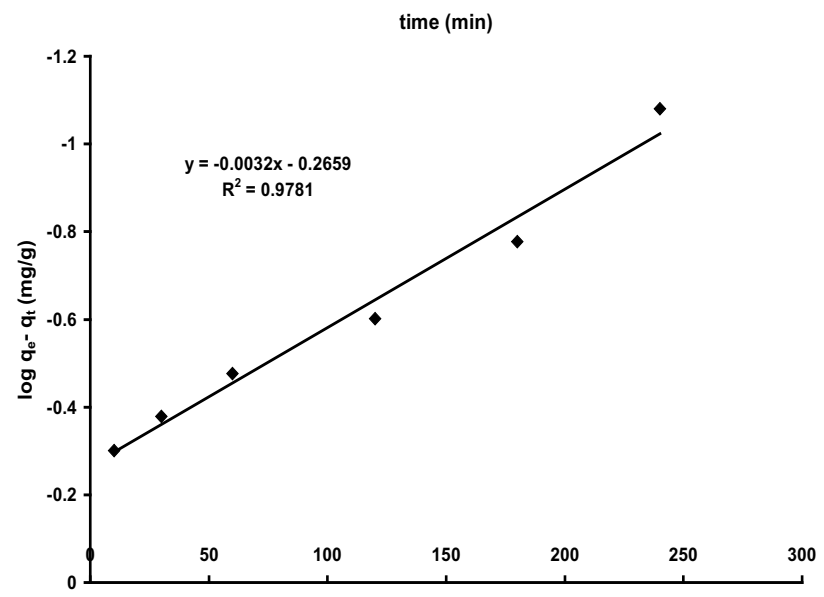

Fig. 6. Pseudo-first order kinetic model for the adsorption of As(III) onto FePDSD

From the kinetic plots of As(III) for the adsorbent it was found that the correlation coefficients $\left(\mathrm{R}^{2}\right)$ for pseudo first order were found to be higher than that of pseudo-second order and second order kinetics for the adsorbent. According to pseudo first order model as shown in Fig. 6, the plot of log qe-qt versus ' $t$ ' gave a straight line with negative slope value. Therefore, the adsorption of As(III) onto FePDSD follows the pseudo-first order kinetic model.

Comparison of the maximum adsorption capacity Comparison of the maximum adsorption capacity (qmax) of the FePDSD with earlier investigated adsorbents as shown in table 2 revealed that the prepared adsorbent possesses higher potentiality towards the adsorptive removal of $\mathrm{As}$ (III) from aqueous solution.

Table 2. Comparison of maximum adsorption capacity

\begin{tabular}{|l|c|c|}
\hline \multicolumn{1}{|c|}{ Adsorbent and Species } & $\begin{array}{c}\text { qmax } \\
\text { (mg/g) }\end{array}$ & Source \\
\hline $\begin{array}{l}\text { Tea fungal biomass towards } \\
\text { As(III) }\end{array}$ & 0.45 & $\begin{array}{c}\text { (Murugesan et al. } \\
\text { 2006) }\end{array}$ \\
\hline Fish scale towards As(III) & 0.24 & (Rahaman et al. 2008) \\
\hline Biotite towards As(III) & 0.30 & $\begin{array}{c}\text { (Chakraborty et al. } \\
\text { 2007) }\end{array}$ \\
\hline FePDSD towards As(III) & 1.33 & (Present work) \\
\hline
\end{tabular}

\section{CONCLUSIONS}

Iron-loaded phosphorylated Dalbergia sissoo sawdust (FePDSD) exhibited appreciable affinity towards As(III) ions. The equilibrium contact time for the adsorption was found to be 300 minutes. The optimum dose of FePDSD was $225 \mathrm{mg}$. The maximum adsorption capacity was found to be $1.33 \mathrm{mg} / \mathrm{g}$ for As(III) onto FePDSD, signifying that the bioadsorbent prepared found to be efficient for the adsorptive removal of As(III) and results revealed that Langmuir adsorption isotherm model was found to be more applicable than Freundlich adsorption isotherm model for the description of the adsorption behavior of As(III) onto FePDSD, signifying the surface homogeneity with respect to active sites. The kinetic data were best fitted to the pseudo-first order kinetic model. Comparison of the maximum adsorption capacity of the FePDSD have shown better results as compared to already investigated materials as shown in the aforementioned table. Thus the bioadsorbent possesses significant potentiality towards the adsorptive removal of As(III) from aqueous solution.

\section{ACKNOWLEDGEMENT}

We would like to acknowledge Head of the Department, Central Department of Chemistry, Tribhuvan University, Kirtipur, Kathmandu, Nepal for providing necessary laboratory facility. 


\section{REFERENCES}

Al-Mamun M., Yousuf M.A. and Subhan M.A. 2009. Efficiency of some bio-adsorbents for mitigation of arsenic from drinking water. J. Bangladesh Chem. Soc. 22: 72-76.

Bailey, S. E., Olin, T.J., Bricka, R.M., Adrian, D.D. 1999. A review of potentially low cost sorbents for heavy metals. Water Res. 33: 2469-2479.

Bohara, K. P. 2005. Investigation on a Simple Technique of Arsenic Removal from Water, M.Sc. Dissertation, Central Department of Chemistry, Tribhuvan University, Nepal.

Chakraborty, S., Wolthers, M., Chatterjee, D., Charlet, L. 2007. Adsorption of arsenite and arsenate onto muscovite and biotite mica. J. Colloid Interf. Sci. 309(2): 392.

Chutia, P., Kato, S., Kojima, T., Satokawa, S. 2009. Arsenic adsorption from aqueous solution on synthetic zeolites. J. Hazard. Mater. 162: 440-447.

Ghimire, K. N., Inoue, K., Yamaguchi, H., Makino, K., Miyajima, T. 2003. Adsorptive separation of arsenate and arsenite anions from aqueous medium by using orange waste. Water Res. 37 (20): 49454953.

Islam, M.J., Hossain, M.R., Yousuf, A., Subhan, M.A. 2007. Removal of arsenic from drinking water using bio-adsorbent. Proc. Pakistan Acad. Sci. 44 (3): 157-164.

Kamsonlian S., Majumder C. B. and Chand S. 2011. Removal of As(III) from aqueous solution by biosorption onto maize (Zea mays) leaves surface: Parameters optimization, sorption isotherm, kinetic and thermodynamics studies. Res. J. Chem. Sci. 1(5): 73-79.

Lee, Y., Um, I., Yoon, J. 2003. Arsenic (III) oxidation by iron (IV) (ferrate) and subsequent removal of arsenic (V) by iron (III) coagulation. Environ. Sci. Technol. 37: 5750-5756.

Lien, H. L., Wilkin, R. T. 2005. High-level arsenite removal from ground water by zerovalent iron. Chemosphere 59: 377-386.

Mamisahebei, S., Jahed Khaniki, Gh.R., Torabian, A., Nasseri, S., Naddafi, K. 2007. Removal of arsenic from an aqueous solution by pretreated waste tea fungal biomass. Iran. J. Environ. Health. Sci. Eng. 4 (2): 85-92.

Mandal, B. K., Suzuki, K. T. 2002. Arsenic round the world: a review. Talanta 58: 201-2035.

Murugesan, G. S., Sathishkumar, M., Swaminathan, K. 2006. Arsenic removal from groundwater by pretreated waste tea fungal biomass. Bioresour. Technol. 97: 483-487.

Neku, A., Tandukar, N. 2003. An overview of arsenic contamination of ground water in Nepal and its removal at household level. Journal de Physique IV: Proceedings 107: 941-944, EDP Sciences.

Nickson, R., McArthur, J., Burgess, W., Ahmed, K. M., Rovenscroft, P., Rahman, M. 1998. Arsenic poisoning of Bangladesh ground water. Nature. 395: 338 .

Rahaman, M.S., Basu, A. and Islam, M.R., 2008. The removal of $\mathrm{As}(\mathrm{III})$ and $\mathrm{As}(\mathrm{V})$ from aqueous solutions by waste materials. Bioresour. Technol. 99: 2815-2823.

Ranjan D., Talat M. and Hasan S.H. 2009. Biosorption of arsenic from aqueous solution using agricultural residue 'rice polish'. J. Hazard. Mater. 166: 1050-1059.

Su, C., Puls, R. W., 2001, Arsenate and arsenite removal by zerovalent iron: kinetics, redox transformation and implications for in situ ground water remediation. Environ. Sci. Technol. 35: 1487-1492.

Sud, D., Mahajan, S., Kaur, M.P. 2008. Agricultural waste material as potential adsorbent for sequestering heavy metal ions from aqueous solutions- A review. Biores. Techno. 99: 6017-6027.

World Health Organization (WHO). 2004. Guidelines for drinking-water quality. 1: Recommendations. Annex 4, Third ed. Geneva.

Wu, Y., Wen, Y., Zhou, J., Cao, J., Jin, Y. and Wu, Y. 2012. Comparative and competitive adsorption of $\mathrm{Cr}(\mathrm{VI}), \mathrm{As}(\mathrm{III})$, and $\mathrm{Ni}(\mathrm{II})$ onto coconut charcoal. Environmental Science and Pollution Research 1: $1-10$.

Yang, J.S., Lee, J.Y., Park, Y.T., Baek, K., Choi, J., 2010. Adsorption of $\mathrm{As}(\mathrm{III}), \mathrm{As}(\mathrm{V}), \mathrm{Cd}(\mathrm{II}), \mathrm{Cu}(\mathrm{II})$, and $\mathrm{Pb}$ (II) from aqueous solutions by natural muscovite. Sep. Sci. Technol. 45: 814-823. 